\title{
Effects of vowel length and syllable structure on segment duration in Dutch
}

\section{Allard Jongman}

Cornell Phonetics Laboratory, Department of Modern Languages, Cornell University, Ithaca, NY 14853-4730, USA

Received 1 April 1997, revised 30 March 1998, accepted 6 April 1998

The present study concerns the durational properties of minimal Dutch word pairs containing long and short vowels as a specific case study of the mapping between phonological and phonetic notions of timing. In Experiment 1, duration of the postvocalic stop consonant in $\mathrm{CV}($ :) Con words did not vary as a function of preceding vowel length. Experiment 2 extended this finding to intervocalic stops in bisyllabic $\mathrm{CV}(:)$ Con words. In Dutch, CV:Con words contain a long vowel in syllable-final position, while CVCon words contain a short vowel followed by an arguably ambisyllabic consonant. Results from Experiment 2 indicated that the duration of the intervocalic consonant is not affected by the quantity of the preceding vowel or its differential status as a tautosyllabic or ambisyllabic consonant. An additional finding of Experiment 2 was that the duration of second-syllable [on] is inversely affected by the length of the vowel in the first syllable. Finally, Experiment 3 established that in $\mathrm{CV}(:) \mathrm{CC}$ ən words, $\mathrm{C} 2$ and, for most speakers, [ən] were longer when preceded by a short vowel in the first syllable. These findings indicate that the presence of a short vowel results in a compensation of approximately $25 \mathrm{~ms}$, which is distributed across the segments following that vowel. It is hypothesized that the postvocalic consonant in Experiments 1 and 2 did not participate in this compensation because the consonant is obligatory following short vowels. Thus, the factor affecting whether or not a postvocalic consonant exhibits compensatory behavior may be not so much ambisyllabicity versus tautosyllabicity but rather its obligatory versus optional status. Implications for models of phonetic and phonological timing are discussed.

(C) 1998 Academic Press

\section{Introduction}

Durational properties of the speech signal have been studied for a variety of languages, including English, Swedish, Estonian, and Dutch. Factors known to influence segment and word durations ${ }^{1}$ range from phonetic and phonological factors to syntactic and

\footnotetext{
${ }^{1}$ One of the reviewers, Dr Roel Smits, correctly pointed out that terms such as vowel or consonant duration mix abstract liguistic units (e.g., vowels, consonants) with concrete physical propeties (e.g., duration). Throughout this paper, the term consonant duration is used elliptically to refer to the interval in the speech signal that includes the closure portion and release burst associated with a particular consonant phoneme. Definitions of the durations of other segments can be found in the relevant analysis sections.
} 
semantic factors. In this paper, we will concentrate on some phonetic and phonological factors influencing segment durations. Early studies typically focused on segmental duration in a linear model. For example, Klatt $(1973 ; 1976)$ proposed that each phonetic segment had an inherent duration and that the phonetic duration of a given segment was the result of a sequence of ordered rules operating on inherent duration as a function of the context in which each phonetic segment occurred. Recent developments in phonological theory have given research on timing a new perspective. Contrary to previous linear representations (e.g., Chomsky \& Halle, 1968), current non-linear phonological approaches (e.g., CV theory: Clements \& Keyser, 1983; moraic phonology: Hyman, 1985; Hayes, 1989) recognize levels for the representation of length, timing, or syllable weight. These approaches also suggest that, in addition to intrinsic segment duration, higher levels of the prosodic hierarchy, such as syllable, foot, and phrase, all jointly determine phonetic duration. Alternatively, there may be no need to make explicit reference to hierarchical syllable structure since syllable structure falls out from patterns of gestural coordination (Browman \& Goldstein, 1995).

Since current phonological theory explicitly makes reference to notions of timing, it is of great theoretical and practical importance that the mapping between phonological and phonetic timing be investigated in detail. Extending Klatt's research, findings by Port, Dalby \& O'Dell (1987), for example, suggest that the mora is a temporally defined unit in the phonetic implementation of Japanese, in that Japanese word durations are almost entirely predicted by the number of moras in a word. More recently, Hubbard (1993) also argues that for the Bantu languages Runyambo and Luganda, mora count is a more relevant timing factor than syllable count.

The present study aims to extend the investigation of the mapping between discrete phonological units and phonetic duration to Dutch. It concerns the durational properties of minimal Dutch word pairs containing long and short vowels as a specific case study of the mapping between phonological and phonetic notions of timing. The difference between short-vowel and long-vowel words has often been described in terms of syllable contact, referring to notions such as "Silbenschnitt" or "Anschluss" (e.g., Sievers, 1881; Jespersen, 1912), or "checked" vs. "free" vowels and "close" vs. "loose" contact (e.g., Heffner, 1952; Jakobson, 1962). These terms refer to the notion that long and short vowels may differ in terms of the transition from the vowel into the following consonant. Contact is said to be loose if the peak intensity of the vowel is followed by a decrease prior to the onset of the following consonant. If the following consonant onset occurs at the peak of the vowel, contact is said to be close. Long vowels are thought to exhibit loose contact, while short vowels exhibit close contact. Earlier onset of the postvocalic consonant in short-vowel words would make this consonant longer in duration as compared to consonants following a long vowel. An explanatory account in terms of close and loose contact would have to be universal, predicting that consonants following short vowels are lengthened in all languages with a vowel length contrast. According to Fischer-Jørgensen (1969), the contact distinction is widely accepted for many Germanic languages, including German, Norwegian, and Dutch. Nooteboom (1972) postulated that increased intensity and duration are the result of abruptly stopping a short vowel without "producing the vowel in a sloppy way" (p. 41). Although the phonetic properties of Dutch have been studied in comparatively great detail, there is remarkably little research on the effect of vowel length on postvocalic consonants.

Data for word-final consonants in monosyllabic words are provided in Nooteboom's (1972) dissertation. Using lip contacts to measure the moments of closing and opening of 
the lips, Nooteboom gathered data for CVrt words spoken by two speakers and showed that the final $/ \mathrm{t} /$ was $40 \mathrm{~ms}$ longer when following a short as compared to a long vowel (139 ms and $179 \mathrm{~ms}$, respectively). Using the same technique, Nooteboom (1972) also provides data for intervocalic consonants in Dutch nonwords of the type [papapap] versus [papapap]. Nooteboom found that the consonant following the stressed short vowel was significantly longer (approximately $10 \mathrm{~ms}$ ) than the consonant following the stressed long vowel. Moreover, for bisyllabic words, the basic textbook on Dutch phonetics (Nooteboom \& Cohen, 1984) reports that the medial consonant following short vowels is substantially longer than that following long vowels. This textbook shows segmented waveforms of the bisyllabic words 'mate' ([matə], 'extent') and 'matte' ([matə], 'dull'). The [t] in 'matte' is much longer in duration $(156 \mathrm{~ms})$ than that in 'mate' (91 ms). In fact, this figure suggests that the total duration of $\mathrm{V}$ plus $\mathrm{C}$ is constant for both the short and long vowel word, indicating a compensation whereby the consonant is lengthened by about the same amount that the vowel is shortened.

However, in a preliminary study, Jongman and Sereno (1991) found no difference in duration between intervocalic consonants following long and short vowels in bisyllabic Dutch words. Recently, Kuijpers (1993) supported the preliminary findings by Jongman and Sereno (1991). Kuijpers' (1993) dissertation focused on the development of the voicing contrast in Dutch children. In one of her experiments, children of ages 4, 6, and 12 , as well as adults, produced 37 bisyllabic words, with a stressed long or short vowel in the first syllable followed by one of the medial consonants $/ \mathrm{p}, \mathrm{b}, \mathrm{t}, \mathrm{d}, \mathrm{k} /$ and then by schwa. Of these 37 words, 28 were of the $\mathrm{CV}($ :)CVC type used by Jongman and Sereno (1991), while 7 were of the CCV(:)CVC type. Kuijpers reported that in none of the age groups was medial consonant duration affected by the length of the preceding vowel.

Indeed, most research on other languages has found no difference in duration between intervocalic consonants preceded by long and short vowels. These languages include Danish, English, and German. In particular, Fischer-Jørgensen (1964) measured closure durations for voiced $/ \mathrm{b}, \mathrm{d}, \mathrm{g} /$ preceded by short and long vowels in 33 Danish nonwords produced by 7 speakers. Sharf (1962) looked at voiced and voiceless medial consonants preceded by four long-short vowel pairs in 8 English words produced by one speaker. Port (1981) investigated medial /b, p/ preceded by /i, I/ in two words and two nonwords of English as produced by 10 speakers. Van Heuven (1992) measured medial /p/ preceded by/e, r/ or /o, o/ in 4 English words produced by five speakers. Finally, Braunschweiler (1994) examined voiced and voiceless medial consonants in 36 German words spoken by four speakers. None of these acoustic studies found any consistent influence of the preceding vowel duration on the duration of the medial consonant. One notable exception is Fischer-Jørgesen (1969), who reported that in German, consonants following short vowels typically have greater airflow, intraoral pressure, and acoustic duration than those following long vowels.

In sum, a few studies report that Dutch consonants following short vowels are longer than those following long vowels. However, the magnitude of this difference varies considerably between studies, ranging from 4-10 ms (Nooteboom, 1972; van Heuven, 1992) to $65 \mathrm{~ms}$ (Nooteboom \& Cohen, 1984). In addition, it is not clear what causes the durational difference, irrespective of its magnitude. Nooteboom's (1972) explanation in terms of a language-universal account under which it takes more articulatory effort to produce a consonant immediately following a short vowel relative to a long vowel, resulting in a longer consonant duration following the short vowel, is not supported by van Heuven's (1992) cross-linguistic study. 
Van Heuven (1992) compared medial obstruents in Dutch and English to determine if consonant lengthening following short vowels was a language-universal or languagespecific phenomenon. Van Heuven claimed that intervocalic stops following short vowels are to be analyzed as geminates in Dutch (an unusual analysis), but not in English. Therefore, if the lengthening effect only occurs in Dutch, it must be a languagespecific effect due to the phonological structure of Dutch. Van Heuven's findings for Dutch medial stop consonants were based on a small corpus produced by 5 speakers (two wordpairs: [kepər]-[kıpər] and [hopən]-[həpən]). Van Heuven's results were qualitatively in agreement with those of Nooteboom and Cohen (1984): For Dutch, a small but significant $4 \mathrm{~ms}$ difference was found. (Recall that Nooteboom and Cohen, 1984, showed a $65 \mathrm{~ms}$ difference in consonant durations.) The duration of consonants following short vowels $(100 \mathrm{~ms})$ was slightly longer than the duration of consonants following long vowels $(96 \mathrm{~ms})$. No such difference was found for English, leading van Heuven to reject a language-universal explanation in terms of close and loose contact.

Overall, then, the claim that the duration of consonants increases following short vowels is questionable in Dutch. Furthermore, it has generally not been supported for languages other than Dutch. These intriguing and discrepant findings warrant a closer and more systematic look at these effects in Dutch, using a variety of minimal word pairs. Data from three sets of experiments will be presented. In Experiment 1 the effect of long and short vowels on segment and syllable durations of CVC words is investigated. These findings are extended to bisyllabic words with a single medial consonant (CVCVC) in Experiment 2. And, finally, Experiment 3 is designed to include medial consonant clusters in CVCCVC words. These three experiments allow for a comprehensive investigation of the nature and the domain of vowel length effects on segment and syllable durations in Dutch.

\section{Experiment 1}

\subsection{Speakers}

Three native speakers of Dutch (one female, two males), all students at Nijmegen University, were recruited for this experiment. They were paid for their participation. They had no known speech or hearing disorders.

\subsection{Materials and procedure}

Thirty test words (15 minimal pairs) were selected (see Appendix A). These word pairs contained one of four long-short vowel pairs ([a]-[a], [o]-[o], [e]-[r], and [o]-[œ] ). All test words had voiceless stop consonants in word-final position to ensure accurate segmentation. These words were embedded in the carrier phrase 'Ik zei _ een keer' (I said__once) in randomized order. Fillers were included to avoid list effects. Short and long vowel words were blocked separately.

All test sentences were recorded in a sound-proof booth at the Max Planck Institute for Psycholinguistics on a DAT-recorder (Sony, TCD1000) with a Sennheiser MD211N microphone. The recordings were analyzed at the Cornell Phonetics Laboratory. 


\subsection{Analysis}

The test words were digitized at $12 \mathrm{kHz}$ and low-pass filtered at $6 \mathrm{kHz}$ using Entropics Waves + Speech analysis software running on a SUN Sparc2. Segment durations were measured from a graphics terminal displaying synchronized waveforms and spectrograms. Specifically, initial consonant duration (C1) was defined as the interval from initial closure up to and including the release burst. F2 offset of the preceding vowel was taken to be the onset of consonant closure. Burst offset was indicated by the abrupt termination of aperiodic energy in the spectrogram. Vowel duration (V) was defined as the interval between F1 onset and F2 offset. Final consonant duration (C2) was defined as the interval between vowel offset and $\mathrm{C} 2$ release burst. All segment durations reported here represent average values across all speakers and test words.

\subsection{Results}

Data showing average segment durations for short and long-vowel stimuli are shown in Fig. 1. For this and all subsequent experiments, the data from all speakers were combined and a repeated measures ANOVA was conducted for each segment duration, with Length as a within factor and Speaker as the repeated factor. Because of the relatively small number of speakers in each experiment, ANOVAs were also conducted for each individual speaker.

There was no statistically significant difference between initial consonants $(\mathrm{C} 1)$ preceding long vowels $(128 \mathrm{~ms})$ as compared to short vowels $(123 \mathrm{~ms})[F(1,2)=1.68$, $p>0.25]$. As expected, long vowels $(190 \mathrm{~ms})$ were substantially longer than short vowels $(105 \mathrm{~ms})[F(1,2)=87.72, p<0.025]$. There was no significant difference between consonants following long vowels $(163 \mathrm{~ms})$ and those following short vowels (166 ms), $[F(1,2)=0.631, p>0.50]$. Finally words containing long vowels $(481 \mathrm{~ms})$ were significantly longer than those containing short vowels $(394 \mathrm{~ms}),[F(1,2)=60.04, p<0.025]$.

Analysis of individual speakers revealed results for C1, V, C2, and WORD that were similar to those of the group analyses.
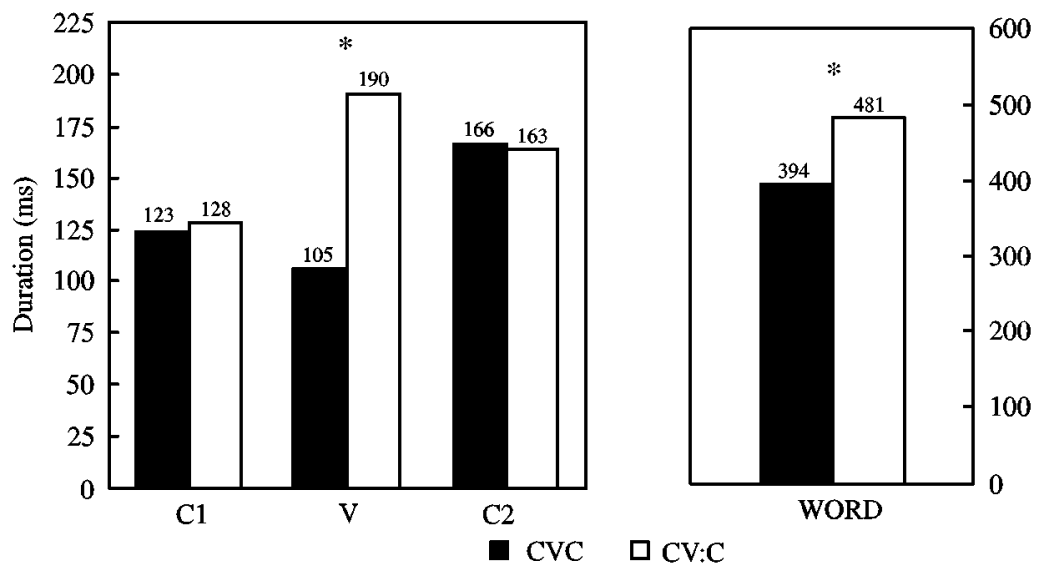

Figure 1. Mean segment durations (across 3 speakers) for minimal CVC pair members containing short and long vowels in Experiment 1. All durations are in ms. Significant differences are indicated by asterisks. 


\subsection{Discussion}

Experiment 1 indicates that the only difference between CVC pairs containing long versus short vowels is in terms of the duration of the vowel itself. That is, the duration of adjacent consonantal segments does not seem to be affected by vowel length. The present finding that the final consonant is not affected by preceding vowel length is contrary to earlier observations (Nooteboom, 1972) but is in agreement with data provided by Port (1981) for English. Port (1981) measured closure durations of final $/ \mathrm{b} /$ and $/ \mathrm{p} /$ as a function of preceding vowel length $(/ \mathrm{i} / \mathrm{vs}$./I/) in $\mathrm{CVC}$ stimuli and found no differences.

\section{Experiment 2}

Experiment 1 did not confirm earlier observations that consonants which follow short vowels in Dutch CVC words are substantially longer than those which follow long vowels. Experiment 2 was therefore designed to further investigate the effects of vowel length when a second syllable was added to the CVC stem. This manipulation made it possible to explore whether or not intervocalic consonants behave like final consonants with respect to effects of preceding vowel length.

\subsection{Methods}

Five native speakers of Dutch (two females, three males), all students at Nijmegen University, were recruited for this experiment. They were paid for their participation. They had no known speech or hearing disorders.

\subsection{Materials and procedure}

Thirty-two test words (16 minimal pairs) were selected. Fifteen of these were plural forms of the words used in Experiment 1. These word pairs contained one of four long-short vowel pairs ([a]-[a], [o]-[o], [e]-[r], and [o]-[œ]) and had voiceless stop consonants in word-medial position to ensure accurate segmentation. In addition, all words ended in [ən], a morphological marker which indicates either a plural noun or a verbal infinitive, and which ensures first-syllable stress. These words were embedded in the carrier phrase 'Ik zei _ twee keer' (I said _ twice) in randomized order. Fillers were included to avoid list effects. Short and long vowel words were blocked separately.

\subsection{Analysis}

All test sentences were recorded in a sound-proof booth at the Max Planck Institute for Psycholinguistics on a DAT-recorder (Sony, TCD1000) with a Sennheiser MD211N microphone. The test words were digitized at $10 \mathrm{kHz}$ and low-pass filtered at $5 \mathrm{kHz}$, using the Max Planck speech analysis software running on a VAX750. Analysis procedures were identical to those described for Experiment 1. The second-syllable morphological marker [ən] was defined as the interval from second-vowel F1 onset to termination of low-frequency nasal murmur. All segment durations reported here represent average values across all speakers and test words. 


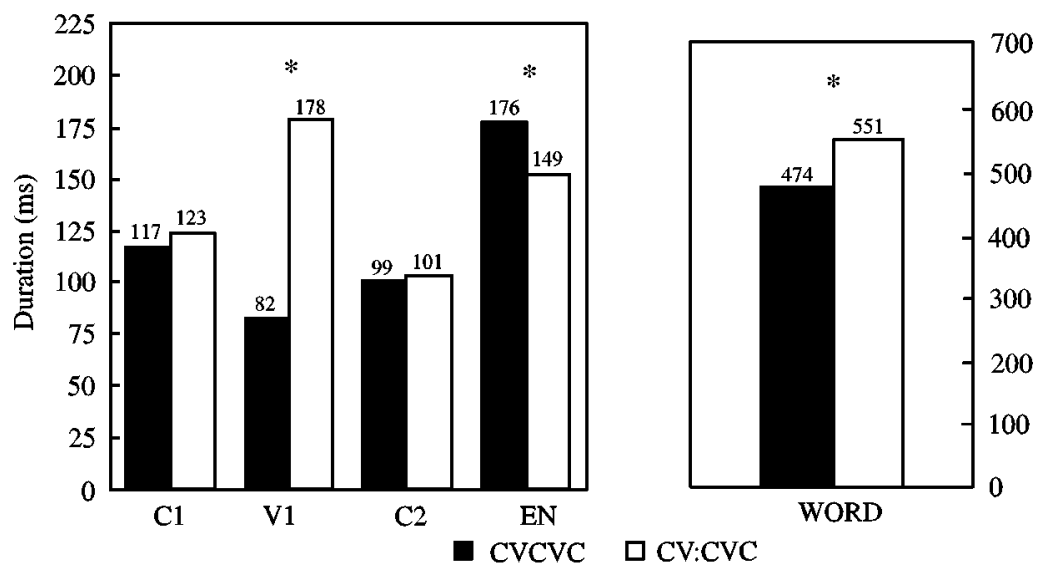

Figure 2. Mean segment durations (across 5 speakers) for minimal CVCVC pair members containing short and long vowels in Experiment 2.

\subsection{Results}

Average segment durations for short and long vowel words are shown in Fig. 2. The data from all five speakers were combined and subjected to a repeated measures ANOVA.

Initial consonants $(\mathrm{C} 1)$ preceding long vowels were significantly longer $(123 \mathrm{~ms})$ than those preceding short vowels $(117 \mathrm{~ms})[F(1,4)=13.41, p<0.025]$. Secondly, as expected, a large difference was found in duration between phonemically long $(178 \mathrm{~ms})$ and short $(82 \mathrm{~ms})$ vowels $[F(1,4)=4,991.7, p<0.001]$. Long vowels were on average approximately $100 \mathrm{~ms}$ longer than short vowels. For the medial consonant (C2), no significant differences in duration were found between long and short vowel word pairs. Contrary to earlier findings, there was no difference in duration between the consonant following a short vowel (99 ms) and that following a long vowel $(101 \mathrm{~ms})[F(1,4)=1.32, p>0.25]$.

A priori, since there was no difference between medial consonants, one might expect that the difference in total word duration between words like [takən] and [takən] would simply amount to the difference in vowel duration between e.g., long [a] and short [a]. Interestingly, however, this was not the case. Although words containing long vowels were significantly longer $(551 \mathrm{~ms})$ than words containing short vowels $(474 \mathrm{~ms})[F(1,4)=$ 142.27, $p<0.005]$, a $77 \mathrm{~ms}$ difference, the mean difference in vowel duration was $96 \mathrm{~ms}$. This $19 \mathrm{~ms}$ difference between word and vowel duration indicates that some segments in short-vowel words had longer durations relative to long-vowel words. If the $6 \mathrm{~ms}$ difference in $\mathrm{C} 1$, which is in the opposite direction, is included, there is a difference of $25 \mathrm{~ms}$ that needs to be accounted for.

Indeed, the duration of [ən] (EN) turned out to significantly differ, depending on whether the first syllable contained a long or a short vowel. The duration of EN was significantly longer when preceded by a first syllable containing a short vowel (176 ms) as compared to a long vowel $(149 \mathrm{~ms})[F(1,4)=17.55, p<0.025]$. Thus, the $26 \mathrm{~ms}$ difference in EN seems to make up for the $25 \mathrm{~ms}$ difference previously observed. It should be noted that in many varieties of Dutch, the final [n] of the [on] sequence can be omitted in casual speech. However, all speakers in the present study retained final $[\mathrm{n}]$ in this corpus of studio-recorded speech. 
Data of individual speakers were very similar to those of the group, except that no speaker showed a significant difference for initial consonant. All speakers showed significant differences for vowel, [ən], and word durations, in the same direction as the group analyses. Finally, speakers 2, 3, 4, and 5 showed no significant differences for medial consonant duration (C2), while Speaker 1 showed a significant difference in the opposite direction $[F(1,15)=15.47, p<0.001]$. For this speaker, consonants following short vowels were shorter $(104 \mathrm{~ms})$ than when following long vowels $(113 \mathrm{~ms})$.

\subsection{Discussion}

Experiment 2 yielded the following results: First, medial stop consonants preceded by either long or short vowels did not significantly differ in terms of their durations. This result is in agreement with Kuijpers (1993) but is contrary to findings for Dutch by Nooteboom (1972), Nooteboom and Cohen (1984), and, most recently, van Heuven (1992). Both Nooteboom and van Heuven report that consonants following short vowels are slightly, but significantly, longer $(4-10 \mathrm{~ms})$ than consonants following long vowels. The $65 \mathrm{~ms}$ difference for medial consonants in 'mate/matte', which was the wordpair reported by Nooteboom and Cohen (1984), cannot be very representative. In addition, psychophysical data indicate that the $4-10 \mathrm{~ms}$ difference is well below the JND. Abel (1972) reports a JND for temporal gaps (comparable to consonant closure) of approximately $30 \mathrm{~ms}$, suggesting that a $4-10 \mathrm{~ms}$ difference is not perceptible.

Van Heuven (1992) used a small corpus (5 speakers, 12 tokens per speaker), comparing productions of the two wordpairs [kepər]-[kıpər] and [hopən]-[həpən]. None of the individual speakers in the present study showed the effect reported by van Heuven (1992). It should be noted that the [ər] ending in van Heuven's study is part of the stem, not a morphological marker, while the [ən] ending is a morphological marker both in his study and in the present one. It is unknown whether morphological status might affect the temporal characteristics of the test words.

It should be pointed out that Nooteboom's (1972) stimuli are perhaps not directly comparable to the present ones. Nooteboom used trisyllabic nonwords with full vowels of the type $\mathrm{pVpVpVp}$, in which the second syllable was stressed, whereas the present study used bisyllabic words with stress on the first syllable, and a reduced vowel in the second syllable. It is unlikely that differences in prosodic environment could account for the discrepancy between the present results and those of earlier studies. The present findings are supported by similar findings for Dutch (Kuijpers, 1993) and for other languages, including Danish (Fischer-Jørgensen, 1964), English (Sharf, 1962; Port, 1981; van Heuven, 1992), and German (Braunschweiler, 1994) across a variety of prosodic contexts.

Additional findings from Experiment 2 show that long vowels were approximately twice as long as their short counterparts, in agreement with many previous studies (e.g., Nooteboom, 1972; Slis \& Cohen, 1969; Lahiri, Schriefers \& Kuijpers, 1987; Jongman, Sereno, Raaijmakers \& Lahiri, 1992; Kuijpers, 1993).

Interestingly, an inverse relationship was found between initial-syllable vowel length and the second-syllable [ən] portion. The duration of [ən] was significantly longer when preceded by a first syllable containing a short vowel as compared to a long vowel. This may be interpreted as an attempt to keep total word duration constant (e.g., Rapp, 1971; Lehiste, 1977). This compensation could be viewed in several ways. It could simply be a matter of vowel length, such that if the first syllable has a long vowel, the second 
syllable will be much shorter. Alternatively, it could be a matter of weight or footing, such that an open initial syllable requires the following syllable to be a lighter unit.

Overall, the results from Experiment 2 thus confirm and expand those from Experiment 1. In Experiment 1, no effect of vowel length on final consonant duration in CVC words was observed. Similarly, in Experiment 2, vowel length did not affect medial consonant duration in bisyllabic CVCVC words. Instead, the second syllable was affected by vowel length.

However, it should be pointed out that the postvocalic consonant may not have the same phonological status in Experiments 1 and 2. Instead, the results for bisyllabic words may be due to the special status of medial consonants following short vowels. In Dutch, long vowels can occur in both open and closed syllables, whereas short vowels occur only in closed syllables. When nouns such as [tak] 'task' and [tak] 'branch' are pluralized by adding the suffix '-en', 'taken' ([takən]) is said to consist of a first open syllable [ta], containing the long vowel [a], and a second syllable [kən] with a tautosyllabic [k], whereas 'takken' ([takən]) consists of the closed syllable [tak], which contains the short vowel [a] and is closed by an ambisyllabic [k] (Booij, 1978). It is important to note that there is a difference between the notion of ambisyllabicity in Dutch and English. In English, it has been suggested that stress determines ambisyllabicity (e.g., Kahn, 1976). By contrast, in Dutch, it has been argued that ambisyllabicity causes a syllable to be closed, thereby attracting stress (e.g., Gussenhoven, 1986). In metrical phonology, these words would be represented as shown in (1).

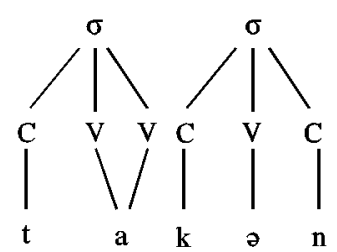

(b)

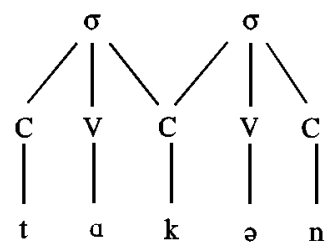

The long [a] in 'taken' (1a) is represented by two vowel slots on the CV tier. For 'takken' (1b), short [a] is represented by one vowel slot, while the ambisyllabicity of medial $[\mathrm{k}]$ is reflected in its attachment to both the first and second syllable (see, for example, Booij, 1978).

This potential difference in phonological representation between tautosyllabic and ambisyllabic medial consonants raises the question whether the contrast in medial consonants in Dutch surfaces as a phonetic difference in consonant duration. Recent phonological analyses do not predict such differences. Van der Hulst (1985a; b) offers an analysis in which ambisyllabic consonants are represented as phonologically long consonants which ultimately surface as phonetically short, similar to tautosyllabic consonants. Indeed, the present results support a phonological analysis under which ambisyllabic and tautosyllabic consonants do not differ phonetically. We will return to the potentially special status of ambisyllabic consonants after Experiment 3.

\section{Experiment 3}

Neither Experiment 1 nor Experiment 2 showed an effect on vowel length on postvocalic consonant duration. However, one could argue that the results of Experiment 2 should 
not be directly compared to those of Experiment 1, since the postvocalic consonant in Experiment 1 was tautosyllabic while in Experiment 2 it was either tautosyllabic or ambisyllabic. Since the phonological status of the postvocalic consonants in these experiments is not comparable, it may be difficult to compare the effect of preceding vowel length on consonant duration across the two conditions. The crucial comparison, then, would involve words with medial consonant clusters, in which there is no doubt about the syllable affiliation of the consonants. The role of vowel length in CVCCVC words, in which the first medial consonant is unambiguously a coda consonant and the second an onset consonant, was therefore investigated in Experiment 3.

\subsection{Methods}

Four native speakers of Dutch (two females, two males) were recruited for this experiment. They were volunteers, with no known speech or hearing disorders.

\subsection{Materials and procedure}

Both word and nonword stimuli were selected. For the word stimuli, eight test words (4 minimal pairs) were selected containing three long-short vowel pairs ([a]-[a], [o]-[o], and $[0]-[œ])$. All test words were past tense forms of verbs. The verb stems had stop consonants in word-initial position and ended in $/ \mathrm{p} /$ or $/ \mathrm{k} /$ to ensure accurate segmentation. To all verb stems, the morphological past tense marker 'ten' was added. Thus, each word had a voiceless medial consonant cluster of either $/ \mathrm{pt} /$ or $/ \mathrm{kt} /$. The structure CV: CCVC is only possible in morphologically complex words.

Since it was difficult to find a sufficiently large set of word pairs, 48 test nonwords (24 minimal pairs) were also selected. The use of nonwords allowed for the inclusion of all four long-short vowel pairs ([a]-[a], [o]-[o], [e]-[1], and [o]-[œ]) used in Experiments 1 and 2 and a greater control over initial consonants. All nonwords had one of the voiceless stop consonants [p, t, k] word-initially and a voiceless medial consonant cluster of either $/ \mathrm{pk} /$ or $/ \mathrm{tk} /$. All nonwords also ended in [ən]. Thus, nonwords were of the type [tepkən], [pitkən], etc. Since the relation between orthography and pronunciation is very transparent in Dutch, subjects had no problems pronouncing the nonwords.

All words and nonwords were first-syllable stressed. Two repetitions of all stimuli were embedded in the carrier phrase 'Ik zei _ twee keer' (I said _ twice) in randomized order. Fillers were included to avoid list effects. Words and nonwords were blocked separately, as were long and short vowel stimuli.

\subsection{Analysis}

All test sentences were recorded in The Netherlands in a quiet room, using a high-quality portable tape recorder (Marantz PMD 222) and an AKG D310 microphone. Analysis procedures were identical to those described for Experiment 1. Since these test words now contained a medial consonant cluster, $\mathrm{C} 2$ indicates the first member of the cluster and $\mathrm{C} 3$ the second member. The duration of $\mathrm{C} 3$ was defined as the interval in between the release burst of $\mathrm{C} 2$ and the onset of the second vowel. For tokens in which $\mathrm{C} 2$ and/or C3 did not exhibit a clear burst, no attempt was made to measure C2 or C3 duration, respectively. This was only the case for a small number of tokens $(9 \%$ of words, $8 \%$ of 


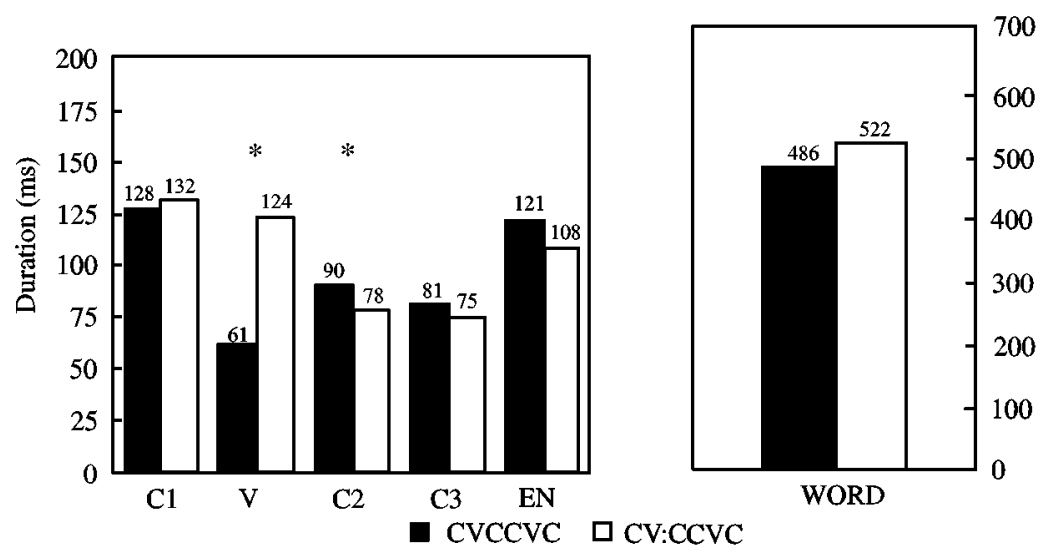

Figure 3. Mean segment durations (across 4 speakers) for minimal CVCCVC pair members containing short and long vowels in Experiment 3.

nonwords). (Non)word offset was defined as the offset of low-frequency nasal murmur. All segment durations reported here represent average values across all speakers and all word and nonword test items.

\subsection{Results}

Average segment durations for short and long-vowel stimuli are shown in Fig. 3. First, an ANOVA was conducted with Length and Lexical Status (Word, Nonword) as independent factors. Since this analysis revealed no significant Length $\times$ Lexical Status interactions for any of the segment durations, subsequent repeated measures ANOVAs were then conducted on the combined word and nonword data.

Initial consonant duration (C1) for short $(128 \mathrm{~ms})$ and long-vowel $(132 \mathrm{~ms})$ stimuli was not significantly different $[F(1,3)=0.284, p>0.50]$. Long vowels $(124 \mathrm{~ms})$ were significantly longer than short vowels $(61 \mathrm{~ms})[F(1,3)=56.35, p<0.005]$. C2 duration was significantly longer for short-vowel stimuli $(90 \mathrm{~ms})$ than for long-vowel stimuli $(78 \mathrm{~ms})$ $[F(1,3)=13.94, p<0.05]$. The difference in C3 duration between short-vowel stimuli $(81 \mathrm{~ms})$ and long-vowel stimuli $(75 \mathrm{~ms})$ was not significant $[F(1,3)=2.59, p>0.10]$. The difference in EN duration between short-vowel stimuli $(121 \mathrm{~ms})$ and long-vowel stimuli $(108 \mathrm{~ms})$ was not significant $[F(1,3)=3.68, p>0.10]$. Finally, long-vowel stimuli $(522 \mathrm{~ms})$ were not significantly longer than short-vowel stimuli $(486 \mathrm{~ms})[F(1,3)=4.12$, $p>0.10]$.

Analysis of each speaker revealed additional patterns. While results for $\mathrm{C} 1, \mathrm{~V}$, and $\mathrm{C} 2$ were very similar to those of the group analysis, C3 duration was significantly different for speaker $1[F(1,27)=10.76, p<0.003]$ and speaker $2[F(1,27)=36.58, p<0.001]$. Duration of EN was significantly different for speaker $1[F(1,27)=16.51, p<0.001]$ and speaker $2[F(1,27)=28.36, p<0.001]$, with speaker 4 displaying a strong trend $[F(1,27)=3.40, p>0.076]$. Finally, WORD duration was significantly different for speaker $1[F(1,27)=37.89, p<0.001]$, speaker $3[F(1,25)=94.43, p<0.001]$, and speaker $4[F(1,23)=24.51, p<0.001]$. 


\subsection{Discussion}

The overall results of Experiment 3 indicate that segments following a short vowel are longer than those following a long vowel. The results suggest a compensatory effect whereby the length of the vowel in the first syllable is, for most speakers, negatively correlated with duration of $\mathrm{C} 2$, with a number of speakers also showing effects for $\mathrm{C} 3$ and [ən].

\section{Conclusions}

The present series of three experiments was an attempt to begin to explore the relationship between phonological and phonetic timing in Dutch. In particular, the timing characteristics of stimuli containing short and long vowels were investigated.

Experiment 1 established that in $\mathrm{CV}(:) \mathrm{C}$ words, consonants preceded by short vowels do not differ in terms of duration from those preceded by long vowels. Data from CV(:) $\mathrm{CVC}$ words in Experiment 2 indicated again that the medial consonant did not differ in duration as a function of preceding vowel length. However, vowel length did affect [ən] duration such that a long vowel was followed by a relatively short [ən] portion. Finally, results for $\mathrm{CV}(:) \mathrm{CCVC}$ words in Experiment 3 showed that this compensation can indeed affect the consonant immediately following the stressed vowel. The postvocalic consonant and, for most speakers, the [ən] portion were affected by the length of the preceding vowel.

Taken together, the results from these three experiments are straightforward and consistent across experiments. In general, the presence of a long stressed vowel seems to result in a compensation on the order of about $25 \mathrm{~ms}$, which is distributed across segments following that vowel. For example, in Experiment 3, $\Delta$ vowel (long vowel short vowel) is $63 \mathrm{~ms}$ while $\Delta$ word is only $36 \mathrm{~ms}$. The relative reduction in overall word duration is primarily carried by $\mathrm{C} 2$ and [ən], which together are $25 \mathrm{~ms}$ shorter in the long vowel words than in the short vowel words. In Experiment 2, the compensation also amounts to $25 \mathrm{~ms}$. However, for these $\mathrm{CV}(:) \mathrm{CVC}$ words, the medial consonant does not participate in this compensation: its duration is unaffected by the duration of the preceding vowel. The question is therefore why this medial consonant does not behave like $\mathrm{C} 2$ in Experiment 3. I suggest here that this difference has to do with the phonological status of the medial consonant. In Experiment 3, C2 participates in the compensatory process. According to the analysis of section 3.5., C2 here is clearly a coda consonant. In contrast, in Experiment 2 the medial consonant following a short vowel is arguably ambisyllabic; that is, it is both a coda and an onset at the same time. The ambiguous role apparently prevents the ambisyllabic consonant from participation in the compensatory process.

One of the insights of a theory of Articulatory Phonology (e.g., Browman \& Goldstein, 1989, 1990) is that (partial) overlap of distinct articulatory gestures may lead to complete assimilation in the acoustic domain. The consonant clusters in Experiment 3 would constitute a context in which overlap of gestures leading to acoustic assimilation would be more expected than in the vowel-consonant sequences in Experiments 1 and 2. Yet, the acoustic differences between consonants are most pronounced in Experiment 3, suggesting that syllable structure has a direct influence on the articulatory and acoustic realization of individual segments. 
Finally, Experiment 1 indicated that the final consonant in $\mathrm{CV}(:) \mathrm{C}$ words did not show any compensatory effects either. Recall that Nooteboom (1972) did show such effects in minimal pairs of the type [port] versus [port]. The difference between Nooteboom's and our findings may be explained in terms of the different phonological role played by the final consonant in both studies. Dutch does not allow open CV syllables with a short vowel in final position. In a word such as [port], the final $/ \mathrm{t} /$ is optional since the $/ \mathrm{r} /$ already ensures that the syllable is well-formed. In contrast, in a word such as [tak], the final $/ \mathrm{k} /$ is obligatory since the syllable would be phonotactically illegal without a final consonant. Nooteboom's and our results combined suggest that compensatory effects show up when the consonant(s) under investigation are not part of the minimum syllable, as is the case for $/ t /$ in both [port] and [port]. However, when the target consonant is obligatory, as in [tak], no compensatory effects are observed. Thus, the crucial parameter here may be not so much ambisyllabicity versus tautosyllabicity but rather obligatoriness versus optionality.

The finding that ambisyllabic consonants did not differ in duration from tautosyllabic consonants goes against earlier phonetic investigations (e.g., Nooteboom, 1972; Nooteboom \& Cohen, 1984; van Heuven, 1992), but is in agreement with phonological analyses of Dutch which do not predict a difference between the two types of consonants (e.g., van der Hulst, 1985). In addition, these data do not support van Heuven's (1992) analysis of consonants following short vowels as geminates.

The compensatory effect whereby the duration of the second syllable is negatively correlated with the length of the vowel in the first syllable can be related to Lahiri and Koreman's (1988) hybrid phonological analysis of Dutch. According to their analysis, the difference in moraic structure between long-vowel and short-vowel words may be compatible with the compensatory effect found in the present study. In moraic phonology, the mora is a phonological unit involved in the determination of syllable weight, such that light syllables are represented by one mora and heavy syllables by two moras. Syllable weight has been shown to play an important role in the phonological systems of natural languages, not just for stress assignment, but also for segmental processes (e.g., Hyman, 1985).

What counts as a heavy or a light syllable varies across languages. Dutch seems to have an exceptional weight opposition, whereby closed VC syllables are heavier than open long vowel (VV) syllables. This weight distinction is problematic in view of the well-established universal generalization that languages that treat closed syllables as heavy will always treat long vowel syllables as heavy as well (McCarthy, 1979; Hyman, 1985).

In Dutch, then, length or quantity does not directly contribute to weight. Lahiri and Koreman (1988) therefore reject the traditional moraic representation in which weight and quantity are represented by the same phonological unit. Instead, they argue that the weight distinction of $\mathrm{VC}$ versus $\mathrm{VV}$ syllables is to be represented separately from the quantity distinction between long and short vowels. Lahiri and Koreman do this by means of a hybrid representation consisting both of a skeletal (CV) tier and a moraic tier. The skeletal tier can be used to represent long vowels as bipositional, whereas the moraic tier can be used to represent long vowels as monomoraic. The generalization that short vowels must be in closed syllables can be accounted for by requiring syllables to dominate at least two skeletal positions, or timing slots. Within this framework, then, 'taken' and 'takken' would be represented 
as in (2):
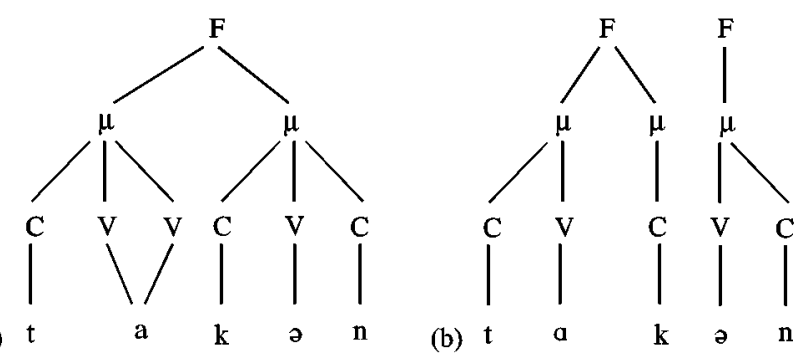

The long vowel in 'taken' (2a) is represented by one mora. The second syllable containing schwa is also represented by one mora. Together these two moras combine into one Foot. For 'takken' (2b), the first syllable is represented by two moras, and the second syllable again by one mora. When building Feet, the two moras of the first syllable combine into one Foot, and the second syllable forms a Foot of its own. In this representation, then, the difference between words like 'taken' and 'takken' becomes obvious: 'taken' consists of two moras and one foot, while 'takken' consists of three moras and two feet.

The puzzling effect of 'en' duration can now be described as follows: the stressless Foot of 'takken' is longer in duration than the weak branch of the foot in 'taken'. In other words, the longer duration of 'en' when following a first syllable with a short vowel may be due to the fact that in this case 'en' forms an independent Foot.

However, Experiment 3, in which vowel length varied but moraic structure was kept constant, showed that moraic structure alone does not control all segment durations, nor does segment count. An alternative analysis of Dutch syllable weight (Kager, 1989) rejects Lahiri and Koreman's (1988) hybrid analysis. Instead, Kager offers a moraic analysis in which the melodic complexity of the syllable rather than the open vs. closed nature of the syllable contributes to syllable weight. While the correct phonological representation is still in dispute, it is clear that any such representation will have to account for the perhaps unusual fact that in Dutch VV counts as light while VC counts as heavy.

Taken together, the present findings suggest that an adequate model of timing must be hierarchical in nature, relating timing at least at the segmental, moraic, syllabic, and word levels. Phonetic research on timing (e.g., Port et al., 1987; Hubbard, 1993) shows that word length is correlated more directly with mora count than syllable count. However, the segment must also play a role, as illustrated by the fact that onsets do not bear weight, yet have intrinsic durations. In addition, phonetic research has shown at least a trend toward isochrony at the word level (e.g., Lehiste, 1977). Recent research by Campbell and Isard (1991) suggests that there are three domains which jointly determine phonetic duration; phrase, syllable, and segment. Along these lines, the present findings suggest a more fine-grained hierarchical model, within the prosodic framework, where duration is assigned at several different levels. Relevant levels indicated by the present study include at least the number of phonemes and syllables, the nature of the stressed nucleus (long versus short vowel), the moraic representation of the syllable, and the position of the syllable in the foot. Further detailed research is needed to determine the contribution of each level in this hierarchy to ultimate phonetic timing patterns. 
I would like to thank Ioana Chitoran, Cisca Custers, Peter Jarich, and Toine Thissen for assistance in data collection and analysis, and Abby Cohn, Aditi Lahiri, Joan Sereno, Juliette Waals, an anonymous reviewer, and the editors for helpful comments. Comments and statistical assistance by reviewer Roel Smits are gratefully acknowledged. This research was supported in part by a grant from the Cornell Society for the Humanities.

\section{References}

Abel, S. M. (1972) Discrimination of temporal gaps, Journal of the Acoustical Society of America, 52, 519-524 Booij, G. (1978) Fonotactische restricties in de generatieve fonologie, Spektator, 8, 29-46

Braunschweiler, N. (1994) Stimmhaftigkeit und Vokallänge im gesprochenen Deutsch: Produktions- und Perzeptionsexperimente zur Bestimmung der akustischen Schlüsselparameter. M.A. thesis, University of Konstanz.

Browman, C. P. \& Goldstein, L. (1989) Articulatory gestures as phonological units, Phonology, 6, 201-251

Browman, C. P. \& Goldstein, L. (1990) Gestural specification using dynamically-defined articulatory structures, Journal of Phonetics, 18, 299-320

Browman, C. P. \& Goldstein, L. (1995) Gestural syllable specification in English. In Producing speech: Contemporary issues (F. Bell-Berti \& L. J. Raphael, editors), pp. 19-33. New York: AIP Press

Campbell, W. N. \& Isard, S. D. (1991) Segment durations in a syllable frame, Journal of Phonetics, 19, 37-47

Chomsky, N. \& Halle, M. (1968) The Sound Pattern of English. New York: Harper \& Row

Clements, G. N. \& Keyser, S. (1983) CV Phonology: A Generative Theory of the Syllable. Cambridge: MIT Press

Fischer-Jørgensen, E. (1964) Sound duration and place of articulation, Zeischrift für Phonetik, 17, 175-207

Fischer-Jørgensen, E. (1969) Untersuchungen zum sogenannten festen und losen Anschluss, Kopenhagener germanistischen Studien, I, 138-164

Gussenhoven, C. (1986) English plosive allophones and ambisyllabicity, Gramma, 10, 119-141

Hayes, B. (1989) Compensatory lengthening in moraic phonology, Linguistic Inquiry, 20, 253-306

Heffner, R. M. S. (1952) General Phonetics. Madison: University of Wisconsin Press.

Heuven, V. van (1992) Linguistic versus phonetic explanation of consonant lengthening after short vowels: A contrastive study of Dutch and English. In Proceedings of the International Conference on Spoken Language Processing, vol. 2 (J. J. Ohala, T. M. Nearey, B. L. Derwing, M. H. Hodge \& G. W. Wiebe, editors), pp. $1275-1277$

Hubbard, K. (1993) Mapping phonological structure to phonetic timing: moras and duration in two Bantu languages, Proceedings of the Berkeley Linguistic Society, 19, 182-192

Hulst, H. van der (1985a) Ambisyllabiciteit en de structuur van Nederlandse lettergrepen, Spektator, 319-326

Hulst, H. van der (1985b) Ambisyllabicity in Dutch. In Linguistics in The Netherlands ed. by H. Bennis \& F. Beukema (pp. 57-66). Dordrecht: Foris

Hyman, L. (1985) A Theory of Phonological Weight. Dordrecht: Foris

Jakobson, R. (1962) Die Betonung und ihre Rolle in der Wort- und Syntagmaphonologie, Selected Writings, 1, 117-136. The Hague: Mouton

Jespersen, O. (1912) Lehrbuch der Phonetik. Leipzig

Jongman, A. \& Sereno, J. A. (1991) On vowel quantity and post-vocalic consonant duration in Dutch, Proceedings of the XIIth International Congress of Phonetic Sciences, Vol. 2, 294-297

Jongman, A., Sereno, J., Raaijmakers, M. \& Lahiri, A. (1992) The phonological representation of [voice] in speech perception, Language \& Speech, 35, 137-152

Kager, R. (1989) A Metrical Theory of Stress and Destressing in English and Dutch. Dordrecht: Foris

Kahn, D. (1976) Syllable-based Generalizations in English Phonology. Doctoral thesis, MIT

Keating, P. A. (1988) Underspecification in phonetics, Phonology, 5, 275-292

Klatt, D. H. (1973) Interaction between two factors that influence vowel duration, Journal of the Acoustical Society of America, 54, 1102-1104

Klatt, D. H. (1976) Linguistic uses of segment duration in English: Acoustic and perceptual evidence, Journal of the Acoustical Society of America, 59, 1208-1221

Kuijpers, C. T. L. (1993) Temporal Coordination in Speech Development. Doctoral thesis, University of Amsterdam

Lahiri, A. \& Koreman, J. (1988) Syllable weight and quantity in Dutch, Papers from the West Coast Conference on Formal Linguistics, 7, 217-228

Lahiri, A., Schriefers, H. \& Kuijpers, C. (1987) Contextual neutralization of vowel length: evidence from Dutch, Phonetica, 44, 91-102

Lehiste, I. (1977) Isochrony reconsidered, Journal of Phonetics, 5, 253-263

McCarthy, J. (1979) On stress and syllabification, Linguistic Inquiry, 10, 443-465 
Nooteboom, S. G. (1972) Production and Perception of Vowel Duration. Doctoral dissertation, University of Utrecht

Nooteboom, S. G. \& Cohen, A. (1984) Spreken en verstaan. Assen: van Gorcum

Port, R. (1981) Linguistic timing factors in combination, Journal of the Acoustical Society of America, 69, 262-274

Port, R., Dalby, J. \& O’Dell, M. (1987) Evidence for mora timing in Japanese, Journal of the Acoustical Society of America, 81, 1574-1585

Rapp, K. (1971) A study of syllable timing, STL-QPSR, 1, 14-19

Sharf, D. J. (1962) Duration of post-stress intervocalic stops and preceding vowels, Language \& Speech, 5, 26-30

Sievers, E. (1881) Grundzu.ge der Phonetik. Leipzig

Slis, I. H. \& Cohen, A. (1969) On the complex regulating the voiced-voiceless distinction, Language \& Speech, 12, $80-102$

\section{Appendix A. Stimuli used in Experiment 1.}

\author{
beet [bet] 'bite' \\ teek [tek] 'tick' \\ beuk [bøk] 'beech' \\ jeuk [jøk] 'itch' \\ boot [bot] 'boat' \\ doop [dop] 'baptism' \\ poot [pot] 'leg' \\ haak [hak] 'hook' \\ jaap [jap] 'slash' \\ kaap [kap] 'cape' \\ maat [mat] 'size' \\ paap [pap] 'priest' \\ raat [rat] 'honeycomb' \\ taak [tak] 'task' \\ zaak [zak] 'case'
}

\author{
bit [bit] 'bit' \\ tik [trk] 'flick' \\ buk [bœk] 'duck' (verb) \\ juk [jœk] 'yoke' \\ bot [bot] 'bone' \\ dop [dop] 'cap' \\ pot [pot] 'jar' \\ hak [hak] 'heel' \\ jap [jap] 'Japanese' \\ kap [kap] 'hood' \\ mat [mat] 'dull' \\ pap [pap] 'porridge' \\ rat [rat] 'rat' \\ tak [tak] 'branch' \\ zak [zak] 'bag'
}

